\title{
Respiração de embriões recalcitrantes de Inga vera Willd. subsp. affinis (DC.) T.D. Pennington sob diferentes temperaturas, potenciais osmóticos e aplicação de ABA
}

\author{
Marcio Roberto Bonjovani ${ }^{1}$ e iD Claudio José Barbedo ${ }^{2,3}$
}

Recebido: 07.01.2020; aceito: 14.05.2020

Como citar: Bonjovani, M.R., \& Barbedo, C.J. respiração de embriões recalcitrantes de Inga vera Willd. subsp. affinis (DC.) T.D. Pennington sob diferentes temperaturas, potenciais osmóticos e aplicação de ABA. Hoehnea 47: e812020. http://dx.doi.org/10.1590/2236-8906-01/2020

\begin{abstract}
Respiration of recalcitrant Inga vera Willd. subsp. affinis (DC.) T.Dw.Pennington embryos under different temperatures, water deficits and ABA application). The high metabolism of desiccation sensitive (recalcitrant) seeds of Inga vera Willd. subsp. affinis (DC.) T.D.Pennington is one of the main factors that hinder the conservation of physiological viability of those seeds during storage. Due to lack of information on the respiratory metabolism of these seeds in different conditions of stress, this study aimed to determine respiration rates of embryos with different levels of hydration and at different temperatures after application of ABA and PEG treatments. The results showed both high levels of respirations and the presence of oxidative reactions. ABA showed little effects, but respiration and oxidative processes were diminished by both soft drying and PEG treatment. Therefore, reducing the storage temperature is efficient in reducing the metabolism, allowing to increase the storage. However, the maturation degree is decisive to better conserve the embryos of Inga vera. Keywords: inga, osmotic stress, PEG, recalcitrant seeds, respiratory metabolism
\end{abstract}

RESUMO - (Respiração de embriões recalcitrantes de Inga vera Willd. subsp. affinis (DC.) T.D.Pennington sob diferentes temperaturas, potenciais osmóticos e aplicação de $\mathrm{ABA}$ ). O elevado metabolismo de sementes sensíveis à dessecação (recalcitrantes) de Inga vera Willd. subsp. affinis (DC.) T.D.Pennington é um dos principais fatores que dificultam a manutenção da viabilidade fisiológica das sementes durante o armazenamento. Devido à falta de informações sobre o metabolismo respiratório dessas sementes em diferentes condições de estresse, este estudo teve como objetivo determinar as taxas de respiração de embriões com diferentes conteúdos de água e em diferentes temperaturas após a aplicação dos tratamentos com ABA e PEG. Os resultados mostraram altos níveis de respiração e presença de reações oxidativas. O ABA mostrou poucos efeitos, mas a respiração e os processos oxidativos foram diminuídos pela secagem leve e pelo tratamento com PEG. Portanto, a redução da temperatura de armazenamento é eficiente na redução do metabolismo, permitindo ampliar o armazenamento, mas a escolha do estádio de maturação é decisiva para melhor conservar os embriões de Inga vera.

Palavras-chave: estresse osmótico, ingá, metabolismo respiratório, PEG, sementes recalcitrantes

\section{Introdução}

O maior desafio atual na ciência da conservação de sementes é a obtenção de tecnologia que permita armazenar sementes sensíveis à dessecação (recalcitrantes), por períodos suficientemente longos para sua inclusão em bancos de germoplasma (Barbedo 2018, Barbedo et al. 2018). A falta dessa tecnologia implica em risco de extinção de diversas espécies, pois o armazenamento de sementes é a forma mais comum de conservação ex situ, já que a semente é a unidade de propagação natural da maioria das espécies de fanerógamas (Santos 2001, Marcos Filho 2015).

De modo geral, a secagem é a forma mais comum de conservar a viabilidade das sementes, permitindo ampliar sua longevidade pela redução das reações metabólicas (Villela \& Peres 2004). A capacidade de armazenamento

1 Escola Estadual Professor Horácio Quáglio, Secretaria da Educação do Estado de São Paulo, Rua Jornal O Trabuco, 309, 06273-060 Osasco, SP, Brasil

2 Instituto de Botânica, Núcleo de Pesquisa em Sementes, Avenida Miguel Stéfano, 3687, 04301-012 São Paulo, SP, Brasil

3 Autor para correspondência: cjbarbedo@yahoo.com.br 
é ampliada, para muitas espécies, quando a redução do teor de água das sementes está associada à diminuição da temperatura do ambiente (Walters et al. 2005, Colville \& Pritchard 2019). Para sementes sensíveis à dessecação, a utilização de inibidores endógenos, como $\mathrm{ABA}$, a regulação da mobilização da água na semente com soluções osmóticas e os estresses hídricos também se mostraram favoráveis para a conservação. Outra opção seria a desidratação parcial, ou seja, a secagem até atingir o menor grau de umidade suportável para a semente (Andréo et al. 2006, Bonjovani \& Barbedo 2008, Chandra et al. 2019).

Durante seu desenvolvimento, as sementes sensíveis à dessecação apresentam atividade metabólica intensa de modo que passam quase que diretamente da fase de desenvolvimento para a de germinação, sem exibir período evidente de latência (Pammenter \& Berjak 2000, Caccere et al. 2013). Como as alterações metabólicas associadas à germinação continuam durante o armazenamento, as sementes tornam-se cada vez mais sensíveis à dessecação; mesmo quando armazenadas em ambiente úmido, perdem rapidamente a viabilidade, havendo necessidade de absorção de quantidade adicional de água para completar o processo de germinação (Pammenter \& Berjak 2000, Marcos Filho 2015). Se não há suficiente quantidade de água, podem ocorrer danos ligados ao metabolismo germinativo, com consequente perda da viabilidade das sementes (Pammenter et al. 1994).

A manutenção dessa intensa atividade requer, provavelmente, elevadas taxas respiratórias e grande consumo de reservas. Durante o período no qual as sementes mantêm intensa atividade, mas não completam a germinação, o metabolismo pode ser desordenado, com consumo de reservas e liberação de radicais livres, ambas as atividades prejudicando a conservação da viabilidade das sementes durante $\mathrm{o}$ armazenamento $\mathrm{e}$, consequentemente, favorecendo sua rápida deterioração (Andréo et al. 2006, Berjak \& Pammenter 2008, Marcos Filho 2015). Uma temperatura mais baixa pode atrasar ou reduzir a taxa absoluta de respiração (Dahal et al. 1996, Parisi et al. 2019). Assim, uma forma de diminuir os efeitos do intenso metabolismo de sementes poderia ser a redução da temperatura do ambiente, pois a temperatura determina a velocidade das reações enzimáticas, afetando as taxas respiratórias (Ruelland \& Zachowski 2010). Contudo, para sementes de uma espécie tropical, como o Inga vera Willd., a redução da temperatura pode se tornar um elemento a mais de estresse.

A conservação de sementes sensíveis à dessecação permanece, portanto, como um desafio para fisiologistas e tecnologistas e pouco se sabe, atualmente, sobre os mecanismos envolvidos em sua rápida deterioração. Os diversos processos metabólicos que ocorrem durante o armazenamento dessas sementes devem, portanto, ser estudados com vistas a um futuro desenvolvimento de tecnologia que permita armazenar essas sementes por longos períodos. Uma importante espécie que apresenta sementes com comportamento recalcitrante, presente na Mata Atlântica, é Inga vera Willd. subsp. affinis (DC.) T.D.Pennington. Suas sementes não sobrevivem a períodos superiores a 90 dias, mesmo sob as condições ideais de armazenamento. Diante do exposto, o presente trabalho teve por objetivo analisar a taxa respiratória dos embriões de Inga vera em diferentes estádios de maturação, com diferentes conteúdos de água e os efeitos da aplicação de ácido abscísico e de déficit hídrico nessas taxas respiratórias sob diferentes temperaturas.

\section{Material e Métodos}

Coleta dos frutos e extração das sementes - Os frutos de Inga vera Willd. subsp. affinis (DC.) T.D. Pennington, foram coletados nos meses de janeiro e dezembro de 2009, de 10 matrizes plantadas na Rodovia dos Bandeirantes, Jundiaí, SP $\left(23^{\circ} 04,914^{\prime} \mathrm{S}, 47^{\circ} 01,436^{\prime} \mathrm{W}\right)$. Após a coleta os frutos foram levados ao Laboratório de Sementes, do Instituto de Botânica, em São Paulo, SP ( $\left.23^{\circ} 37^{\prime} \mathrm{S}, 46^{\circ} 32^{\prime} \mathrm{W}\right)$, onde foram abertos manualmente. As sementes foram removidas, agrupadas em dois estádios de maturação (estádios III e IV, segundo Bonjovani \& Barbedo 2008, com sarcotesta pouco e muito espessa, respectivamente, porém já suculenta em ambas) e, em seguida, tiveram sua sarcotesta removida, obtendo-se os embriões excisados utilizados nos experimentos. O material foi armazenado em sacos plásticos, em câmara tipo BOD ajustada para temperatura constante de $6{ }^{\circ} \mathrm{C}$ (Bonjovani \& Barbedo 2008, 2019), sem luz, por até sete dias, período este necessário para que todo o lote coletado fosse beneficiado.

Determinações físicas e fisiológicas - Os embriões foram caracterizados, inicialmente, quanto ao teor de água, conteúdo de massa seca, potencial hídrico, condutividade elétrica da solução de embebição e germinação. $\mathrm{O}$ teor de água e o conteúdo de massa seca foram determinados gravimetricamente, pelo método de estufa a $103{ }^{\circ} \mathrm{C}$ por 17 horas (Brasil 2009), com três repetições de 10 embriões.

O potencial hídrico foi medido por meio de potenciômetro WP4 (Decagon Devices, Inc., Pullman, EUA), basendo-se na temperatura do ponto de orvalho do ar em equilíbrio com a amostra examinada, com três repetições de três embriões. Para aferição do potencial hídrico real dos embriões e do potencial registrado pelo potenciômetro, amostras foram incubadas em soluções de polietileno glicol 6000 com diferentes potenciais osmóticos, segundo Michel \& Kaufmamm (1973), até peso constante, sendo então avaliadas no potenciômetro.

A condutividade elétrica foi determinada por meio de condutivímetro digital de bancada MA150 (Marconi, Piracicaba, Brasil), com três repetições de 10 embriões. Para tanto, amostras de sementes foram acondicionadas em copos plásticos descartáveis de $300 \mathrm{~mL}$, contendo 75 $\mathrm{mL}$ de água deionizada, incubados por 24 horas em câmara tipo BOD ajustada para temperatura constante de $20^{\circ} \mathrm{C}$, sem luz (Barbedo \& Cicero 1998). 
O teste de germinação foi conduzido em rolo de papel para germinação, com duas folhas para a base e outra para cobertura, pré-umedecidas na proporção de duas vezes e meia o peso do papel (Brasil 2009), com três repetições de 20 embriões, colocados em germinadores Marconi tipo MA400 (Marconi, Piracicaba, Brasil), com circulação interna de água, regulados para a temperatura constante de $25^{\circ} \mathrm{Ce}$ luz constante (Bilia \& Barbedo 1997). As avaliações foram realizadas a cada dois dias, durante 14 dias, sendo registrados os embriões germinados (protrusão de raiz primária com, no mínimo, $1 \mathrm{~cm}$ ). Como a espécie produz sementes poliembriônicas, os embriões contidos em cada semente foram mantidos juntos em todas as avaliações. Mesmo quando houve protrusão de mais de uma raiz primária, apenas uma raiz por embrião foi registrada (Bilia \& Barbedo 1997).

Incubação de embriões e avaliação de taxas respiratórias - As taxas respiratórias (aeróbicas e anaeróbicas) e a presença de outras reações oxidativas foram estimadas pela avaliação do consumo de oxigênio $\left(\mathrm{O}_{2}\right)$ e da produção de dióxido de carbono $\left(\mathrm{CO}_{2}\right)$ de embriões incubados em frascos herméticos, segundo metodologia descrita por Lamarca (2009) e Parisi et al. (2019). Os embriões foram acondicionados em embalagens de vidro de $600 \mathrm{~mL}$, hermeticamente fechados, com tampas perfuradas, formando orifícios que foram recobertos por um septo de borracha; por este septo foi inserida uma agulha $(8,0 \times 0,3 \mathrm{~mm})$ conectada a tubo flexível para condução da amostra do ar da embalagem ao interior do equipamento. Antes da introdução dos embriões nas embalagens, foram determinados as massas frescas e o volume desses embriões. $\mathrm{O}$ volume total do ar das embalagens foi determinado segundo o princípio da hidrostática para que se calculasse o volume resultante do ar depois de descontado o volume ocupado pelos embriões.

$\mathrm{O}$ fechamento das embalagens e o acondicionamento dos vidros em BODs, em temperaturas pré-determinadas (descritas adiante), foi determinado como sendo o início do experimento, o tempo zero correspondendo à atmosfera normal ( $21 \%$ de oxigênio e $0,03 \%$ de dióxido de carbono). $\mathrm{O}$ consumo de $\mathrm{O}_{2}$ e a produção de $\mathrm{CO}_{2}$ pelos embriões embalados foram estimados pela diferença entre os valores medidos e os da atmosfera normal. Após cada medida, as embalagens foram abertas por alguns minutos para reequilíbrio com a atmosfera normal, sendo, em seguida, novamente fechadas para a continuidade do experimento. Considerando-se a pressão atmosférica local como 0,90 atm (IAG/USP, 2017), os valores obtidos em porcentagem de $\mathrm{O}_{2}$ ou de $\mathrm{CO}_{2}$ foram convertidos para pressão parcial do gás, segundo a fórmula $\mathrm{p}_{1} / \mathrm{P}=\mathrm{v}_{1} \%$ / V\% (Feltre 2004), sendo " $p_{1}$ " a pressão parcial do gás (em atm), "P" a pressão atmosférica local (0,90 atm), " $\mathrm{v}_{1} \%$ " o volume do gás, em porcentagem e "V\%" o volume total (100\%).

A seguir, baseando-se no volume das embalagens e na temperatura registrada em cada avaliação, os valores foram convertidos para $\mu \mathrm{mol}$ de $\mathrm{O}_{2}$ e de $\mathrm{CO}_{2}$, pela equação $\mathrm{p}_{1} \mathrm{~V}$ $=\mathrm{nRT}$, de Clapeyron, sendo "V" o volume total de ar do frasco (em L), "n" o número de mols do gás, "R" a constante universal dos gases perfeitos $\left(0,082\right.$ atm.L.mol $\left.{ }^{-1} \cdot \mathrm{K}^{-1}\right)$ e "T" a temperatura (em Kelvin).

Baseando-se em experimentos prévios da média de consumo diário de $\mathrm{O}_{2}$ e de liberação de $\mathrm{CO}_{2}$ pelos embriões de Inga vera (dados não publicados), as avaliações foram realizadas no intervalo de um dia para embriões incubados em temperaturas acima de $0{ }^{\circ} \mathrm{C}$ e a cada cinco dias para embriões incubados em temperaturas abaixo de $0{ }^{\circ} \mathrm{C}$. Os valores obtidos nas avaliações foram somados e divididos pela massa seca total da amostra de embriões e pelo número de dias em que os embriões permaneceram nas embalagens, obtendo-se o valor expresso em micromol por grama de massa seca por dia $\left(\mu \mathrm{mol}_{\mathrm{gMS}}{ }^{-1} . \mathrm{d}^{-1}\right)$. Foi calculado, também, o quociente respiratório $(\mathrm{QR})$, dividindo-se o valor obtido para produção de $\mathrm{CO}_{2}$ pelo obtido para consumo de $\mathrm{O}_{2}(\mathrm{QR}$ $\left.=\mathrm{CO}_{2} \cdot \mathrm{O}_{2}^{-1}\right)$, ambos em $\mu \mathrm{mol} \cdot \mathrm{gMS}^{-1} \cdot \mathrm{d}^{-1}$, segundo descrito por Kader \& Saltveit (2002).

Taxas respiratórias de embriões em diferentes conteúdos de água após aplicação de ácido abscísico e solução osmótica - embriões foram submetidos a dois tratamentos de estresse: regulador vegetal (ácido abcísico - $\mathrm{ABA}, 100 \mu \mathrm{M}$, conforme Barbedo \& Cicero 2000) e solução osmótica (solução de polietileno glicol 6000 (PEG), -2,5 MPa conforme Michel \& Kaufmann 1973, ligeiramente mais negativo que o potencial hídrico dos embriões, ou seja, $-0,8$ a $-1,5 \mathrm{MPa}$ segundo Andréo et al. 2006 e Bonjovani \& Barbedo 2014). Os embriões foram incubados em bandejas plásticas $(36,5 \mathrm{x}$ $26,0 \times 7,0 \mathrm{~cm}$ ) com tampa, opacas, com duas folhas de papel de germinação no fundo, cobertos por uma terceira folha. Permaneceram submersos nas soluções de PEG e sobre uma lâmina de solução de $\mathrm{ABA}$ por 24 horas, em BOD a $6 \pm 1{ }^{\circ} \mathrm{C}$. Ao final da incubação, os embriões foram lavados em água corrente, tiveram o excesso superficial de água removido em papel filtro e, em seguida, foram acondicionados nas embalagens de vidro, como descrito acima e incubados a -2 , $2,5,10$ e $15^{\circ} \mathrm{C}$, para avaliações das taxas respiratórias. Ao final, foram novamente avaliados física e fisiologicamente, conforme descrito anteriormente.

Após a aplicação de ABA e PEG os embriões foram submetidos a três conteúdos de água. Os embriões obtidos, separados por estádio de maturação, com e sem a aplicação de ABA e PEG, após retirada amostra controle (sem secagem), foram submetidas a dois níveis de secagem $\left(1^{\mathrm{a}} \mathrm{e} 2^{\mathrm{a}}\right.$ secagens) a $30 \pm 1{ }^{\circ} \mathrm{C}$ (Bilia et al. 1998), por até $48 \mathrm{~h}$, atingindo os teores de água de 55 e $45 \%$. Para tanto, amostras de embriões foram retiradas periodicamente e avaliadas quanto a sua massa, até que atingissem valores próximos aos desejados. Ao final de cada nível de secagem e da incubação para as avaliações das taxas respiratórias, os embriões foram novamente avaliados quanto às suas qualidades físicas $\mathrm{e}$ fisiológicas, conforme descrito anteriormente.

Delineamento experimental e análise estatística dos dados - o delineamento experimental utilizado foi o inteiramente casualizado, com três repetições, em esquema fatorial $3 \mathrm{x}$ 
5 (pré-tratamentos $\mathrm{x}$ temperaturas de incubação), dentro de cada nível de secagem e cada estádio de maturação, para as avaliações de respiração; em esquema fatorial $3 \times 3$ × 2 (nível de secagem x pré-tratamentos $\mathrm{x}$ estádio de maturação), para as avaliações que antecederam as incubações de respiração; e 3 x 3 x 5 (nível de secagem x pré-tratamentos $\mathrm{x}$ temperaturas de incubação), separadamente para cada estádio de maturação, para as avaliações que sucederam as incubações de respiração. Os resultados obtidos foram analisados pelo teste $\mathrm{F}$ e as médias foram comparadas entre si pelo teste de Tukey, sempre ao nível de 5\% (Santana \& Ranal 2004).

\section{Resultados e Discussão}

Embriões de Inga vera classificados como III e IV apresentaram, inicialmente, $66,5 \%$ e $63,1 \%$ de água, em base úmida (tabela 1), e 0,23 e 0,34 g.semente ${ }^{-1}$ de massa seca, respectivamente, o que pode indicar dois diferentes estádios de maturação. Esses teores de água dos embriões corresponderam a água retida com tensões próximas a -1 MPa (tabela 1). Nessa faixa de potencial hídrico, a água é classificada como tipo 5 (Vertucci 1993), ou seja, apresenta características de uma solução diluída e não se liga às macromoléculas (Marcos Filho 2015). É interessante ressaltar que, nesse nível de hidratação e de disponibilidade de água, os embriões podem até mesmo germinar (Vertucci \& Farrant 1995, Marcos Filho 2015).

A incubação dos embriões em ABA pouco alterou o teor de água e o potencial hídrico, porém, a incubação em PEG $(-2,5 \mathrm{MPa})$, promoveu uma leve redução no teor de água de $66,5 \%$ para $62,9 \%$, indicando que houve saída de água (tabela 1). Como os embriões apresentavam, inicialmente, aproximadamente $-1 \mathrm{MPa}$, seria esperado que a maior movimentação de água ocorresse justamente do maior para o menor potencial (Taiz \& Zeiger 2004). Curiosamente, porém, o potencial hídrico dos embriões não entrou em equilíbrio com a solução de PEG, sugerindo algum mecanismo de controle de saída de água, ou que o tempo de incubação não foi suficiente para esse equilíbrio.

Após as secagens, os embriões dos estádios III e IV apresentaram teor de água próximo a 53,6\% e 46,0\% e potencial hídrico de cerca de $-3 \mathrm{MPa}$ e $-5 \mathrm{MPa}$, respectivamente para a $1^{\mathrm{a}}$ e $2^{\mathrm{a}}$ secagens (tabela 1 ). As secagens proporcionaram modificações nas propriedades da água, chegando ao tipo 3 , ou seja, retida com tensões de -4 a -11 MPa (Vertucci 1993). A partir desse nível de hidratação há alteração na atividade fisiológica, a respiração é intensificada e há favorecimento a danos oxidativos (Marcos Filho 2015).

A condutividade elétrica dos embriões do estádio III aumentou com as secagens (tabela 2), demonstrando os danos promovidos às membranas devido à dessecação, não demonstrados pela porcentagem de germinação (tabela 3 ), pois a condutividade elétrica da solução de embebição avalia a integridade das membranas celulares (Marcos Filho 2015). Esses resultados coincidem com os obtidos por Bilia et al. (1998), que avaliaram os efeitos da secagem sobre a viabilidade dos embriões de $I$. vera. A elevada diferença no valor da condutividade elétrica, dos embriões do estádio III, após as secagens, reforça a hipótese de que esses embriões são mais imaturos, pois o sistema de membranas atinge a máxima organização durante a fase final do acúmulo de massa seca (Marcos Filho 2015).

Taxas respiratórias de embriões em diferentes conteúdos de água após aplicação de ácido abscísico e solução osmótica - de modo geral, as variações na taxa respiratória variaram conforme o estádio de maturação, a temperatura, os prétratamentos e o nível de secagem (figuras 1 a 6). Nas temperaturas mais elevadas os resultados demonstraram o elevado metabolismo dos embriões que, segundo diversos autores, é um dos principais responsáveis pela dificuldade em se armazenar sementes recalcitrantes por longos períodos (Pammenter et al. 1994, Pammenter \& Berjak 2000, Berjak \& Pammenter 2008, Barbedo et al. 2013, Barbedo 2018). À medida que se diminuiu a temperatura, como era de se esperar, houve correspondente redução na respiração, vista pela produção de $\mathrm{CO}_{2}$ desses embriões. Contudo, surpreendentemente mesmo a $5^{\circ} \mathrm{C}$, temperatura de câmara fria considerada favorável para a conservação desses embriões (Bilia \& Barbedo 1997, Bilia et al. 1998, Andréo et al. 2006, Faria 2006, Bonjovani \& Barbedo 2008), ainda houve intensa respiração. Assim como observado por Bonjovani \& Barbedo (2019), mesmo em temperatura negativa $\left(-2^{\circ} \mathrm{C}\right)$ os embriões mantiveram-se metabolicamente ativos.

A variação no consumo de $\mathrm{O}_{2}$ (figuras 1 a e 4 a), na faixa das temperaturas favoráveis para conservação destes embriões $\left(2\right.$ e $\left.5^{\circ} \mathrm{C}\right)$, não foi semelhante à liberação de $\mathrm{CO}_{2}$ (figuras $1 \mathrm{~b}$ e $4 \mathrm{~b}$ ), resultando em valores de $\mathrm{QR}$ entre 0,2 e 0,4 (figuras $1 \mathrm{c}$ e 4 c). O elevado consumo de $\mathrm{O}_{2}$, sem equivalente liberação de $\mathrm{CO}_{2}$, poderia significar a presença de outras reações que não a respiração, tais como a peroxidação de lipídios e a oxidação de compostos fenólicos com a liberação do radical superóxido e que podem estar envolvidos com a deterioração das sementes (Hendry 1993, Bailly 2004, Marcos Filho 2015, Berjak \& Pammenter 2008, Berjak et al. 2011).

Em relação aos diferentes estádios de maturação, verificou-se que os embriões mais imaturos (estádio III, figura $1 \mathrm{a}, \mathrm{b}$ ) respiraram mais intensamente do que os mais maduros (estádio IV, figura $4 \mathrm{a}, \mathrm{b}$ ). Contudo, quanto mais baixa a temperatura de incubação, mais os valores entre os estádios se aproximaram.

De maneira geral, o consumo de $\mathrm{O}_{2}$ e a liberação de $\mathrm{CO}_{2}$, nos embriões do estádio IV, não apresentaram grandes alterações com as secagens (figuras 5 e 6). A primeira secagem resultou em $\mathrm{QR}$ próximo a 1,0, indicando respiração equilibrada e a segunda secagem, por sua vez, resultou em QR acima de 1,0, o que pode indicar a fermentação pelo 
Tabela 1. Teor de água (\%) e potencial hídrico (-MPa) de embriões de Inga vera Willd. subsp. affinis (DC.) T.D.Pennington de dois estádios de maturação (III e IV), submetidos a pré-tratamentos com solução de ABA $\left(10^{-4} \mathrm{M}\right)$ ou de PEG $(-2,5 \mathrm{MPa}) \mathrm{e}$ submetidos a três níveis de secagem (sem secagem, $1^{\mathrm{a}}$ secagem e $2^{\mathrm{a}}$ secagem). Médias seguidas pela mesma letra (minúsculas para comparação nas colunas, maiúsculas para comparação nas linhas e itálico para comparação de potencial hídrico entre estádios de maturação) não diferem entre si pelo teste de Tukey a 5\%. Para teor de água a interação entre os três fatores não foi significativa, apenas as interações secagem x pré-tratamentos e secagem x estádios de maturação.

Table 1. Water content (\%) and water potential (-MPa) of Inga vera Willd. subsp. affinis (DC.) T.D.Pennington embryos from two maturation ages (III and IV), submitted to pre-treatments with ABA $\left(10^{-4} \mathrm{M}\right)$ or PEG solution $(-2.5 \mathrm{MPa})$ and submitted to three drying levels (without drying, $1^{\text {st }}$ drying and $2^{\text {nd }}$ drying). Means followed by the same letter (lower case for column comparison, upper case for line comparison and italics for water potential comparison between maturation ages) do not differ by the Tukey test at 5\%. For water content, the interaction among the three factors was not significant, only the drying $\mathrm{x}$ pretreatment and drying $\mathrm{x}$ maturation ages interactions.

\begin{tabular}{|c|c|c|c|c|c|c|}
\hline \multirow{2}{*}{$\begin{array}{l}\text { Pré-tratamentos/ } \\
\text { Estádios de maturação }\end{array}$} & \multicolumn{6}{|l|}{ Secagens } \\
\hline & Sem secagem & & $1^{\mathrm{a}}$ secagem & & $2^{\mathrm{a}}$ secagem & \\
\hline & Teor de água (\%) & & & & & \\
\hline Controle & 66,5 & $\mathrm{aA}$ & 53,1 & $\mathrm{aB}$ & 46,0 & $\mathrm{aC}$ \\
\hline ABA & 65,1 & $\mathrm{abA}$ & 53,4 & $\mathrm{aB}$ & 46,5 & $\mathrm{aC}$ \\
\hline PEG & 62,9 & $\mathrm{bA}$ & 54,2 & $\mathrm{aB}$ & 45,3 & $\mathrm{aC}$ \\
\hline Estádio III & 66,5 & $\mathrm{aA}$ & 53,7 & $\mathrm{aB}$ & 46,1 & $\mathrm{aC}$ \\
\hline Estádio IV & 63,1 & $\mathrm{bA}$ & 53,5 & $\mathrm{aB}$ & 45,8 & $\mathrm{aC}$ \\
\hline \multirow[t]{3}{*}{ Coeficiente de variação } & $3,2 \%$ & & & & & \\
\hline & \multicolumn{6}{|c|}{ Potencial hídrico (-MPa) } \\
\hline & Estádio III & & & & & \\
\hline Controle & 0,8 & $\mathrm{aC} a$ & 3,8 & $\mathrm{aB} a$ & 5,5 & $\mathrm{aA} a$ \\
\hline ABA & 1,3 & $\mathrm{aC} a$ & 3,2 & $\mathrm{aB} a$ & 4,7 & $\mathrm{bA} a$ \\
\hline \multirow[t]{2}{*}{ PEG } & 1,4 & $\mathrm{aC} a$ & 3,4 & $\mathrm{aB} a$ & 4,3 & $\mathrm{bA} a$ \\
\hline & Estádio IV & & & & & \\
\hline Controle & 1,0 & $\mathrm{aC} a$ & 2,8 & $\mathrm{bB} b$ & 4,9 & $\mathrm{aA} b$ \\
\hline ABA & 1,2 & $\mathrm{aC} a$ & 3,4 & $\mathrm{abB} a$ & 4,8 & $\mathrm{aA} a$ \\
\hline PEG & 1,4 & $\mathrm{aC} a$ & 3,7 & $\mathrm{aB} a$ & 4,8 & $\mathrm{aA} a$ \\
\hline Coeficiente de variação & $10,2 \%$ & & & & & \\
\hline
\end{tabular}

desenvolvimento de fungos, como observado por Parisi et al. (2019). As grandes alterações, porém, ocorreram nos embriões do estádio III (figura 2), para os quais a primeira secagem resultou em menores taxas de respiração (nas temperaturas mais elevadas) e de oxidação (nas mais baixas). Este resultado pode estar associado aos efeitos benéficos que se obtém, algumas vezes, quando se submetem sementes recalcitrantes a pequenas secagens antes de seu armazenamento, como verificado por Bilia et al. (1998), ou quando se pretende aumentar a tolerância ao frio, como visto por Bonjovani \& Barbedo (2008). Os valores de condutividade elétrica (tabelas 4 e 5) e de germinação (tabelas 6 e 7) dos embriões, ao final de sua incubação, confirmam esse efeito positivo da pequena secagem. Especialmente para 
Tabela 2. Condutividade elétrica ( $\mu$ S.g-1.cm-1) de embriões de Inga vera Willd. subsp. affinis (DC.) T.D.Pennington de dois estádios de maturação (III e IV), submetidos a pré-tratamentos com solução de ABA (10-4 M) ou de PEG (-2,5 MPa) e submetidos a três níveis de secagem. Médias seguidas pela mesma letra (minúsculas para comparação entre pré-tratamentos, maiúsculas entre os conteúdos de água, itálicas entre estádios de maturação) não diferem entre si pelo teste de Tukey a 5\%.

Table 2. Electrical conductivity $\left(\mu \mathrm{S} . \mathrm{g}^{-1} \cdot \mathrm{cm}^{-1}\right)$ of Inga vera Willd. subsp. affinis (DC.) T.D.Pennington embryos from two maturation ages (III and IV), submitted to pre-treatments with ABA $\left(10^{-4} \mathrm{M}\right)$ or PEG solution $(-2.5 \mathrm{MPa})$ and submitted to three drying levels. Means followed by the same letter (lower case for pre-treatments comparison, upper case for water content comparision and italics for maturation ages comparision) do not differ by the Tukey test at $5 \%$.

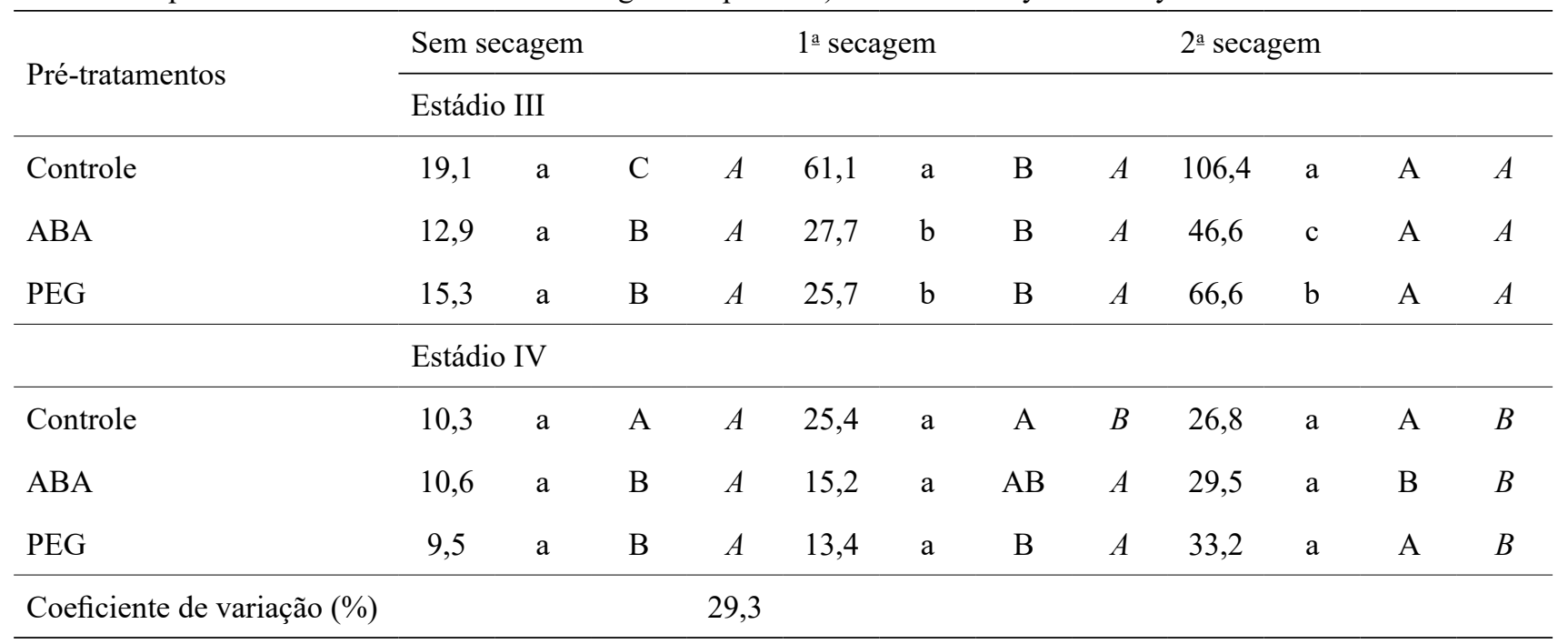

Tabela 3. Germinação (\%) de embriões de Inga vera Willd. subsp. affinis (DC.) T.D.Pennington (média de dois estádios de maturação), submetidos a pré-tratamentos com solução de ABA (10-4 M) ou de PEG (-2,5 MPa) e submetidos a três níveis de secagem. Médias seguidas pela mesma letra (minúsculas para comparação entre pré-tratamentos e maiúsculas entre os conteúdos de água) não diferem entre si pelo teste de Tukey a 5\%.

Table 3. Germination (\%) of Inga vera Willd. subsp. affinis (DC.) T.D.Pennington embryos (mean of two maturation ages), submitted to pre-treatments with ABA $\left(10^{-4} \mathrm{M}\right)$ or PEG solution $(-2.5 \mathrm{MPa})$ and submitted to three drying levels. Means followed by the same letter (lower case for pre-treatments comparison and, upper case for water content comparision) do not differ by the Tukey test at $5 \%$.

\begin{tabular}{|c|c|c|c|c|c|c|}
\hline Pré-tratamentos & Sem secagem & & $1^{\text {a }}$ secagem & & $2^{\mathrm{a}}$ secagem & \\
\hline Controle & 93,3 & $\mathrm{aA}$ & 86,7 & $\mathrm{bA}$ & 94,2 & $\mathrm{abA}$ \\
\hline $\mathrm{ABA}$ & 95,8 & $\mathrm{aA}$ & 97,5 & $\mathrm{aA}$ & 87,5 & $\mathrm{bB}$ \\
\hline PEG & 100,0 & $\mathrm{aA}$ & 97,5 & $\mathrm{aA}$ & 97,5 & $\mathrm{aA}$ \\
\hline Coeficiente de variação (\%) & & & 6,2 & & & \\
\hline
\end{tabular}

embriões do estádio III incubados a $-2{ }^{\circ} \mathrm{C}$, ficou evidente o benefício da primeira secagem que ainda apresentavam $95 \%$ de germinação, enquanto os não submetidos a qualquer secagem já estavam com $69 \%$ de germinação (tabela 6). A segunda secagem promoveu prejuízos tanto à germinação quanto ao sistema de membranas para ambos os estádios de maturação e em todas as temperaturas (tabelas 4, 5, 6 e 7), provavelmente por ter atingido teor de água abaixo do crítico para as sementes dessa espécie (próximo a 50\%, Bilia \& Barbedo 1997, Bilia et al. 1998).
O benefício da primeira secagem também foi verificado quando a remoção da água ocorreu pela exposição dos embriões a déficit hídrico, com o pré-tratamento com PEG. Embriões do estádio III submetidos ao PEG apresentaram redução tanto na taxa respiratória a 10 e $15^{\circ} \mathrm{C}$ (visto pelos resultados de liberação de $\mathrm{CO} 2$, figura $1 \mathrm{~b}$ ) quanto na de oxidação a 5 e $2{ }^{\circ} \mathrm{C}$ (visto pelos resultados de consumo de $\mathrm{O}_{2}$ e QR, respectivamente figura 1 a e c). Já os embriões do estádio IV, por sua vez, tratados com PEG, tiveram redução da respiração a 10 e $15^{\circ} \mathrm{C}$ (figura 4). Contudo, os 

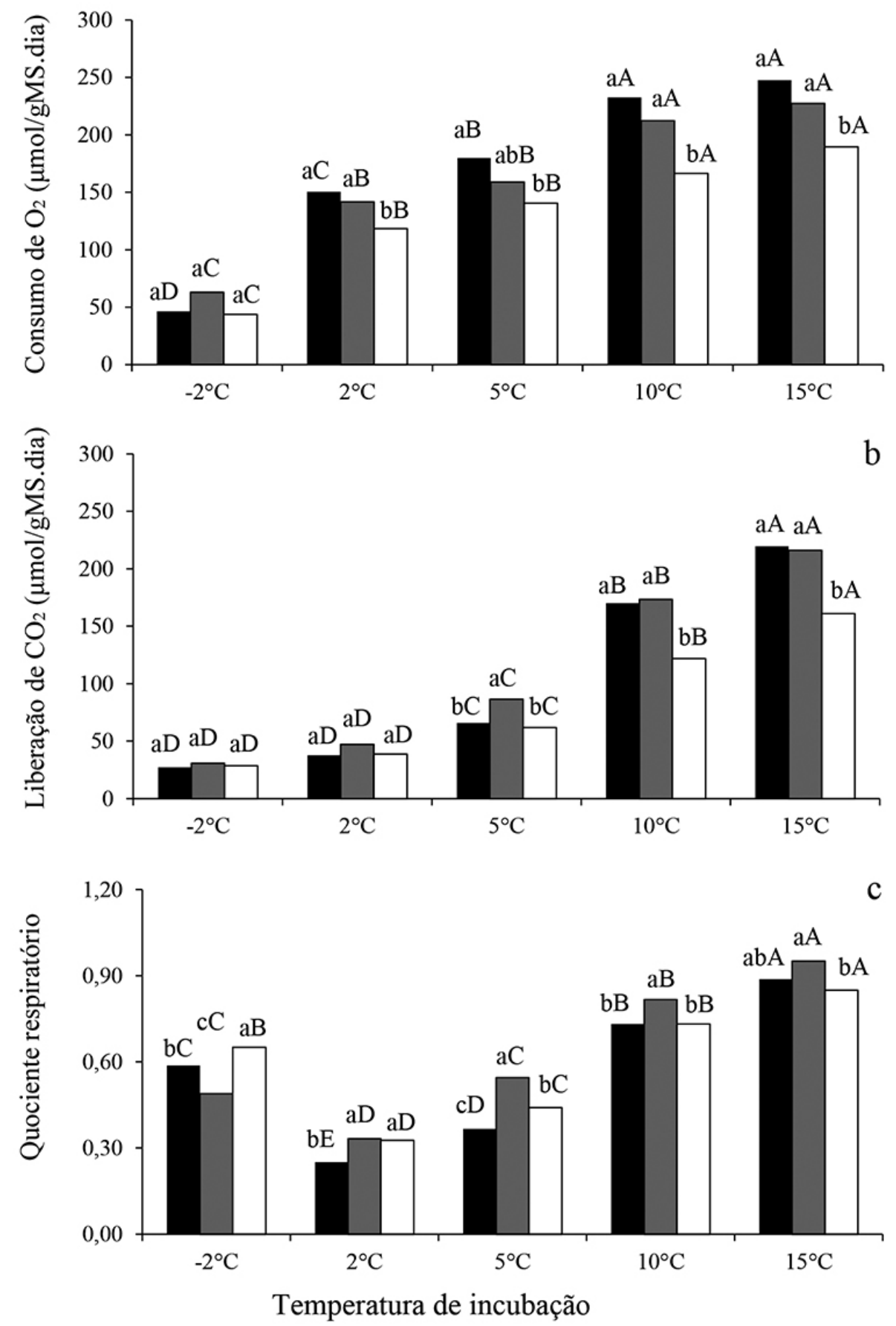

Figura 1. Consumo de oxigênio (a), produção de dióxido de carbono (b) e quociente respiratório (c) de embriões de Inga vera Willd. subsp. affinis (DC.) T.D.Pennington do estádio III, sem pré-tratamento (colunas em preto) ou submetidos a prétratamentos com solução de ABA $10^{-4} \mathrm{M}$ (colunas em cinza) ou de PEG -2,5 MPa (colunas em branco), sem secagem (66,5\% de água) e incubados durante 15 dias a $-2{ }^{\circ} \mathrm{C}$ e 10 dias nas demais temperaturas. Colunas com a mesma letra (minúsculas para comparação entre pré-tratamentos, maiúsculas entre temperaturas) não diferem entre si pelo teste de Tukey a $5 \%$.

Figure 1. Oxygen consumption (a), carbon dioxide production (b) and respiratory quotient (c) of Inga vera Willd. subsp. affinis (DC.) T.D.Pennington embryos at age III, without pretreatment (columns in black) or submitted to pre-treatments with ABA $10^{-4} \mathrm{M}$ solution (columns in gray) or PEG $-2.5 \mathrm{MPa}$ (columns in white), without drying (66.5\% water content) and incubated for 15 days at $-2{ }^{\circ} \mathrm{C}$ and 10 days at other temperatures. Columns with the same letter (lower case for pretreatments comparison, upper case for temperatures) do not differ by the Tukey test at $5 \%$. 

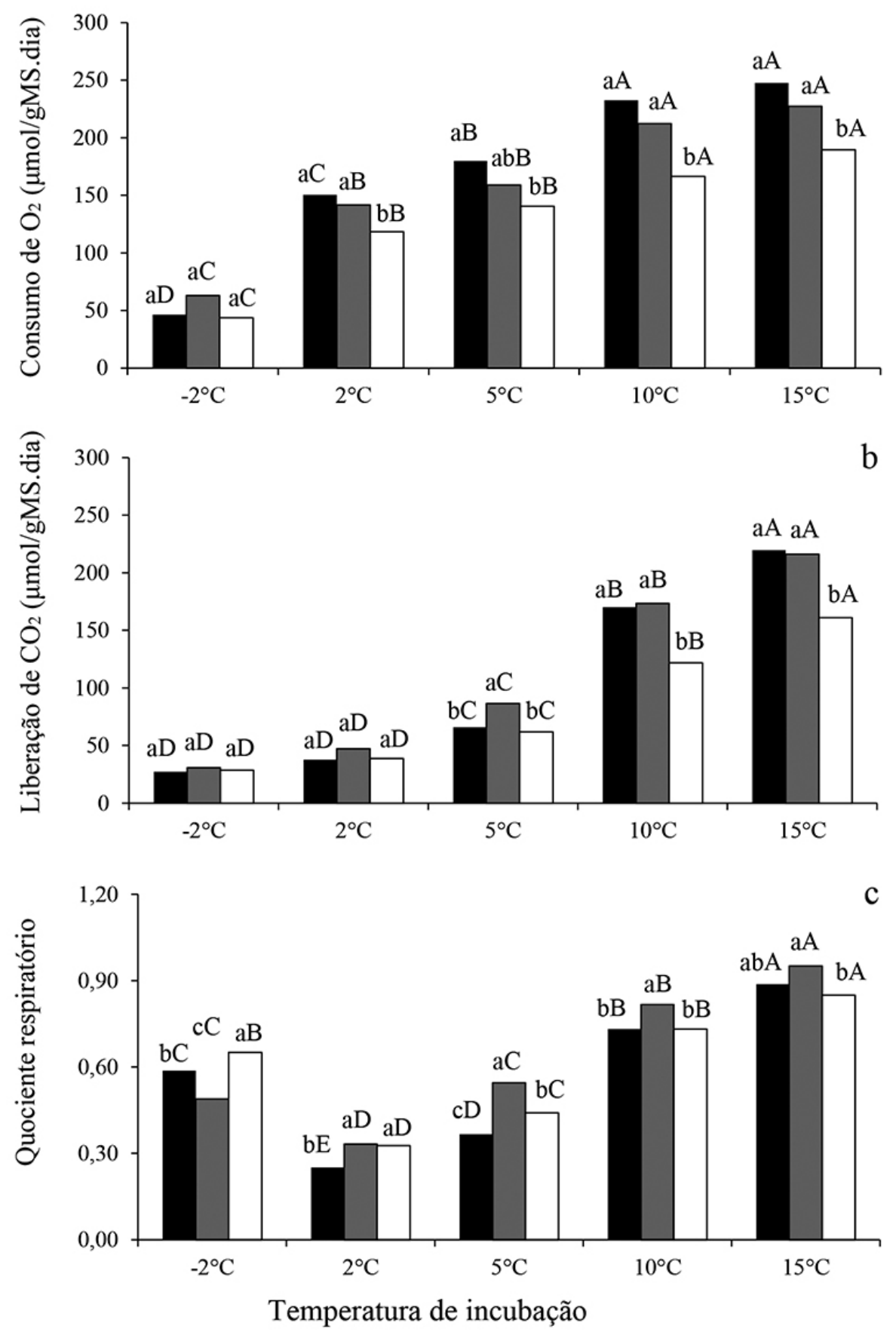

Figura 2. Consumo de oxigênio (a), produção de dióxido de carbono (b) e quociente respiratório (c) de embriões de Inga vera Willd. subsp. affinis (DC.) T.D.Pennington do estádio III, sem pré-tratamento (colunas em preto) ou submetidos a pré-tratamentos com solução de $\mathrm{ABA} 10^{-4} \mathrm{M}$ (colunas em cinza) ou de PEG -2,5 MPa (colunas em branco), após a primeira secagem $\left(53,7 \%\right.$ de água) e incubados durante 15 dias a $-2{ }^{\circ} \mathrm{C}$ e 10 dias nas demais temperaturas. Colunas com a mesma letra (minúsculas para comparação entre pré-tratamentos, maiúsculas entre temperaturas) não diferem entre si pelo teste de Tukey a $5 \%$.

Figure 2. Oxygen consumption (a), carbon dioxide production (b) and respiratory quotient (c) of Inga vera Willd. subsp. affinis (DC.) T.D.Pennington embryos at age III, without pretreatment (columns in black) or submitted to pre-treatments with ABA $10^{-4} \mathrm{M}$ solution (columns in gray) or PEG -2.5 MPa (columns in white), after first drying drying (53.7\% water content) and incubated for 15 days at $-2{ }^{\circ} \mathrm{C}$ and 10 days at other temperatures. Columns with the same letter (lower case for pre-treatments comparison, upper case for temperatures) do not differ by the Tukey test at $5 \%$. 
a
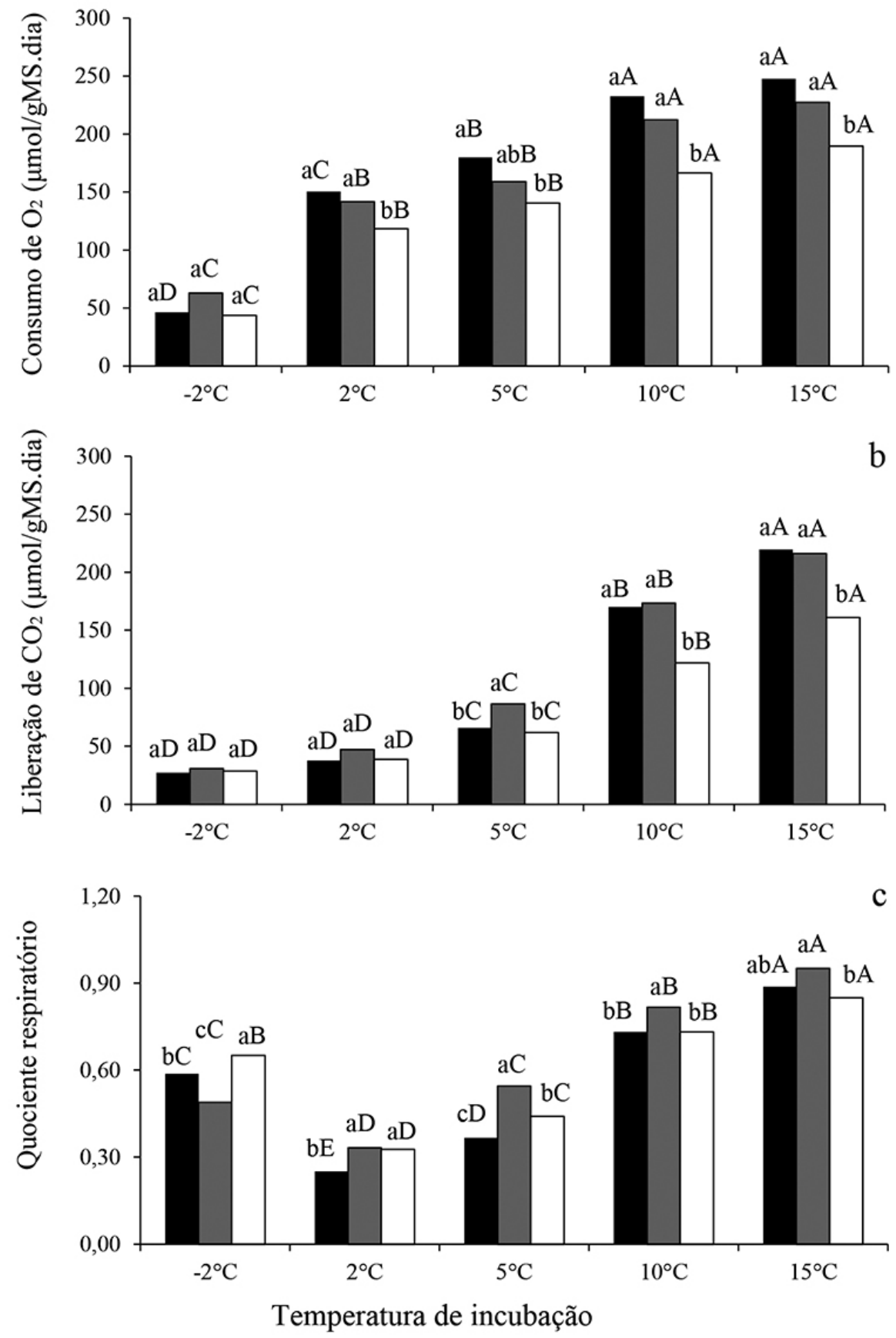

Figura 3. Consumo de oxigênio (a), produção de dióxido de carbono (b) e quociente respiratório (c) de embriões de Inga vera Willd. subsp. affinis (DC.) T.D.Pennington do estádio III, sem pré-tratamento (colunas em preto) ou submetidos a pré-tratamentos com solução de ABA $10^{-4} \mathrm{M}$ (colunas em cinza) ou de PEG -2,5 MPa (colunas em branco), após a segunda secagem $\left(46,1 \%\right.$ de água) e incubados durante 15 dias a $-2{ }^{\circ} \mathrm{C}$ e 10 dias nas demais temperaturas. Colunas com a mesma letra (minúsculas para comparação entre pré-tratamentos, maiúsculas entre temperaturas) não diferem entre si pelo teste de Tukey a $5 \%$.

Figure 3. Oxygen consumption (a), carbon dioxide production (b) and respiratory quotient (c) of Inga vera Willd. subsp. affinis (DC.) T.D.Pennington embryos at age III, without pretreatment (columns in black) or submitted to pre-treatments with $\mathrm{ABA} 10^{-4} \mathrm{M}$ solution (columns in gray) or PEG $-2.5 \mathrm{MPa}$ (columns in white), after second drying (46.1\% water content) and incubated for 15 days at $-2{ }^{\circ} \mathrm{C}$ and 10 days at other temperatures. Columns with the same letter (lower case for pretreatments comparison, upper case for temperatures) do not differ by the Tukey test at $5 \%$. 

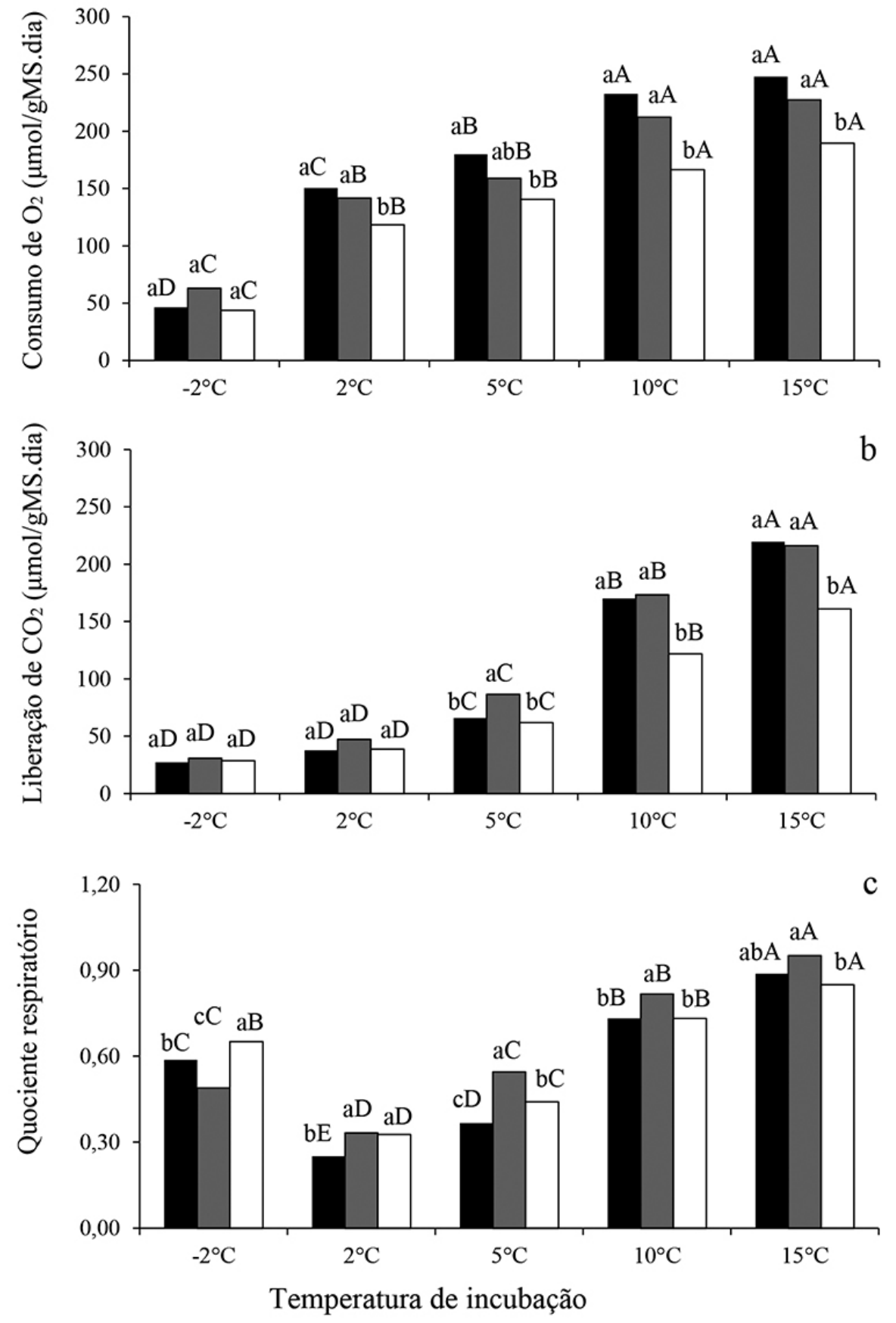

Figura 4. Consumo de oxigênio (a), produção de dióxido de carbono (b) e quociente respiratório (c) de embriões de Inga vera Willd. subsp. affinis (DC.) T.D.Pennington do estádio IV, sem pré-tratamento (colunas em preto) ou submetidos a prétratamentos com solução de ABA $10^{-4} \mathrm{M}$ (colunas em cinza) ou de PEG -2,5 MPa (colunas em branco), sem secagem (63,1\% de água) e incubados durante 15 dias a $-2{ }^{\circ} \mathrm{C}$ e 10 dias nas demais temperaturas. Colunas com a mesma letra (minúsculas para comparação entre pré-tratamentos, maiúsculas entre temperaturas) não diferem entre si pelo teste de Tukey a 5\%.

Figure 4. Oxygen consumption (a), carbon dioxide production (b) and respiratory quotient (c) of Inga vera Willd. subsp. affinis (DC.) T.D.Pennington embryos at age IV, without pretreatment (columns in black) or submitted to pre-treatments with ABA $10^{-4} \mathrm{M}$ solution (columns in gray) or PEG $-2.5 \mathrm{MPa}$ (columns in white), without drying (63.1\% water content) and incubated for 15 days at $-2{ }^{\circ} \mathrm{C}$ and 10 days at other temperatures. Columns with the same letter (lower case for pretreatments comparison, upper case for temperatures) do not differ by the Tukey test at $5 \%$. 

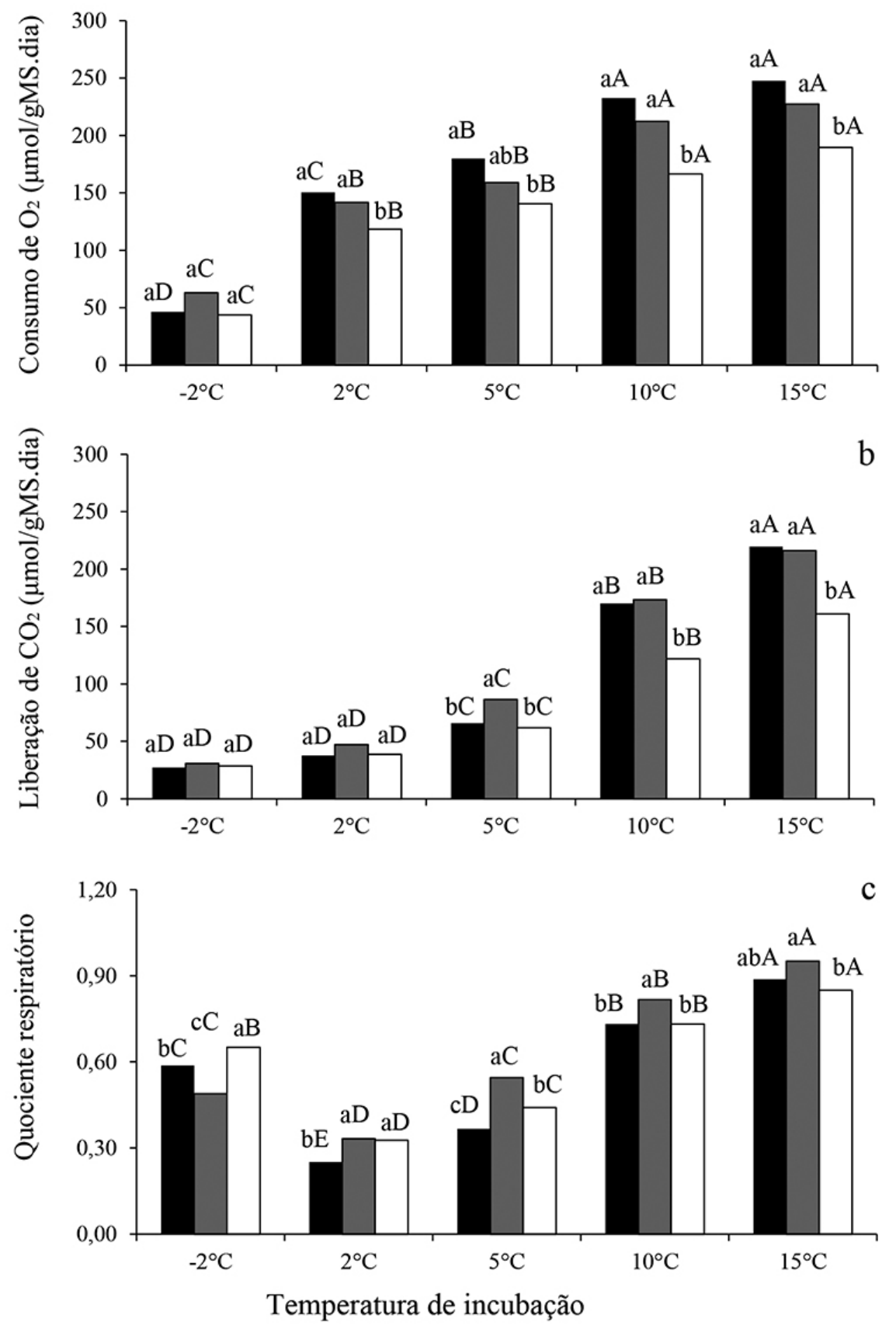

Figura 5. Consumo de oxigênio (a), produção de dióxido de carbono (b) e quociente respiratório (c) de embriões de Inga vera Willd. subsp. affinis (DC.) T.D.Pennington do estádio IV, sem pré-tratamento (colunas em preto) ou submetidos a pré-tratamentos com solução de $\mathrm{ABA} 10^{-4} \mathrm{M}$ (colunas em cinza) ou de PEG -2,5 $\mathrm{MPa}$ (colunas em branco), após a primeira secagem $\left(53,5 \%\right.$ de água) e incubados durante 15 dias a $-2{ }^{\circ} \mathrm{C}$ e 10 dias nas demais temperaturas. Colunas com a mesma letra (minúsculas para comparação entre pré-tratamentos, maiúsculas entre temperaturas) não diferem entre si pelo teste de Tukey a $5 \%$.

Figure 5. Oxygen consumption (a), carbon dioxide production (b) and respiratory quotient (c) of Inga vera Willd. subsp. affinis (DC.) T.D.Pennington embryos at age IV, without pretreatment (columns in black) or submitted to pre-treatments with ABA $10^{-4} \mathrm{M}$ solution (columns in gray) or PEG $-2.5 \mathrm{MPa}$ (columns in white), after first drying drying (53.5\% water content) and incubated for 15 days at $-2{ }^{\circ} \mathrm{C}$ and 10 days at other temperatures. Columns with the same letter (lower case for pre-treatments comparison, upper case for temperatures) do not differ by the Tukey test at $5 \%$. 

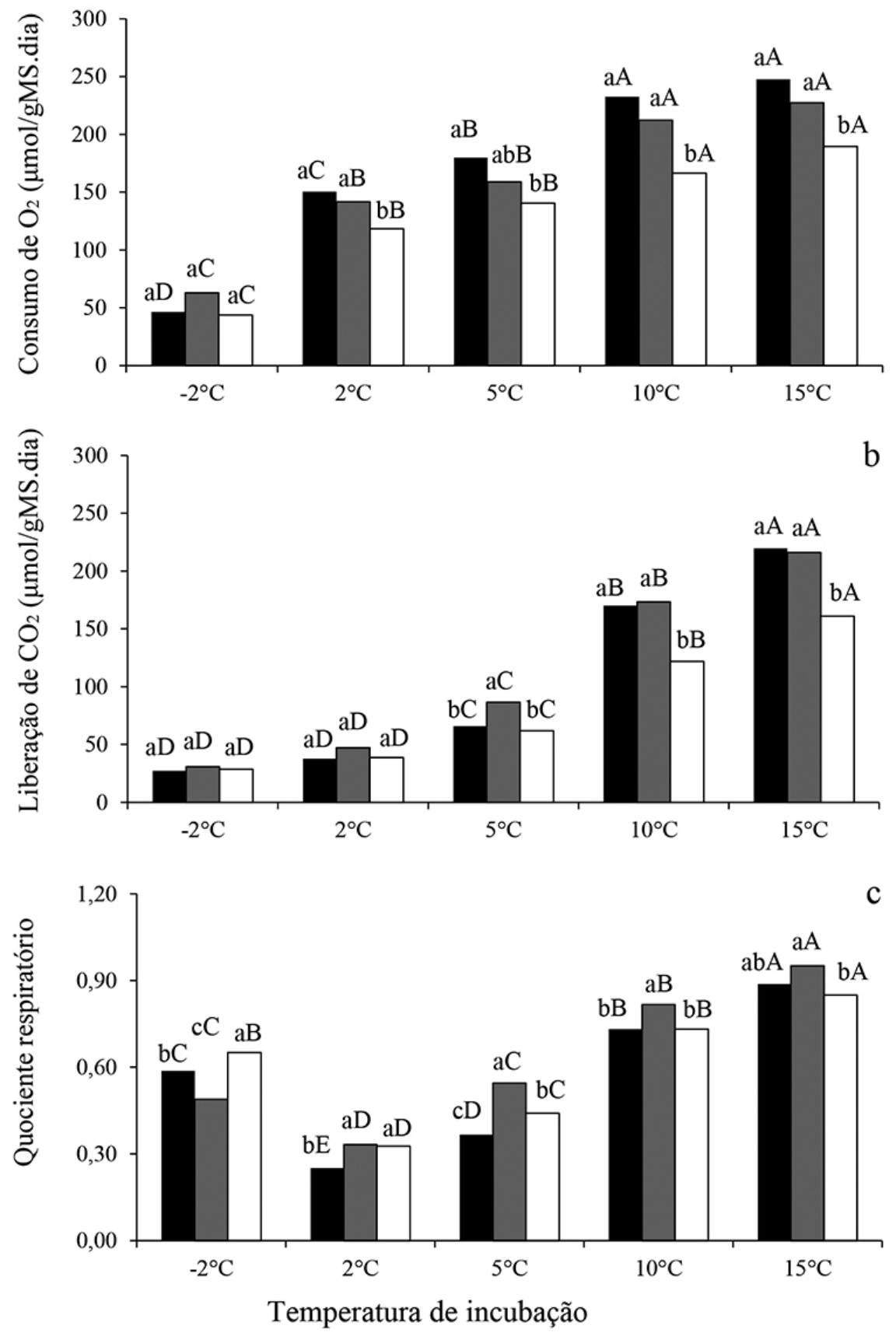

Figura 6. Consumo de oxigênio (a), produção de dióxido de carbono (b) e quociente respiratório (c) de embriões de Inga vera Willd. subsp. affinis (DC.) T.D.Pennington do estádio IV, sem pré-tratamento (colunas em preto) ou submetidos a pré-tratamentos com solução de ABA $10^{-4} \mathrm{M}$ (colunas em cinza) ou de PEG -2,5 MPa (colunas em branco), após a segunda secagem $\left(45,8 \%\right.$ de água) e incubados durante 15 dias a $-2{ }^{\circ} \mathrm{C}$ e 10 dias nas demais temperaturas. Colunas com a mesma letra (minúsculas para comparação entre pré-tratamentos, maiúsculas entre temperaturas) não diferem entre si pelo teste de Tukey a $5 \%$.

Figure 6. Oxygen consumption (a), carbon dioxide production (b) and respiratory quotient (c) of Inga vera Willd. subsp. affinis (DC.) T.D.Pennington embryos at age IV, without pretreatment (columns in black) or submitted to pre-treatments with ABA $10^{-4} \mathrm{M}$ solution (columns in gray) or PEG $-2.5 \mathrm{MPa}$ (columns in white), after second drying (45.8\% water content) and incubated for 15 days at $-2{ }^{\circ} \mathrm{C}$ and 10 days at other temperatures. Columns with the same letter (lower case for pretreatments comparison, upper case for temperatures) do not differ by the Tukey test at $5 \%$. 
Tabela 4. Condutividade elétrica ( $\mu \mathrm{S}$. g-1 . cm-1) de embriões de Inga vera Willd. subsp. affinis (DC.) T.D.Pennington do estádio III, submetidos a pré-tratamentos com solução de ABA (10-4 M) ou de PEG (-2,5 MPa), submetidos a três níveis de secagem e incubados durante 15 dias a $-2{ }^{\circ} \mathrm{C}$ e 10 dias nas demais temperaturas. Médias seguidas pela mesma letra (minúsculas para comparação entre temperaturas, maiúsculas conteúdo de água) não diferem entre si pelo teste de Tukey a 5\%.

Table 4. Electrical conductivity $\left(\mu \mathrm{S} . \mathrm{g}^{-1} \cdot \mathrm{cm}^{-1}\right)$ of Inga vera Willd. subsp. affinis (DC.) T.D.Pennington embryos from age III, submitted to pre-treatments with ABA $\left(10^{-4} \mathrm{M}\right)$ or PEG solution $(-2.5 \mathrm{MPa})$, submitted to three drying levels and incubated 15 days at $-2{ }^{\circ} \mathrm{C}$ and 10 days at other temperatures. Means followed by the same letter (lower case for temperature comparison, upper case for water content comparision) do not differ by the Tukey test at $5 \%$.

\begin{tabular}{lccc}
\hline Temperaturas & Níveis de secagem & \\
\cline { 2 - 4 }$\left({ }^{\circ} \mathrm{C}\right)$ & Inicial & $1^{\mathrm{a}}$ secagem & $2^{\mathrm{a}}$ secagem \\
\hline-2 & $33,0 \mathrm{aB}$ & $22,2 \mathrm{aB}$ & $51,2 \mathrm{dA}$ \\
2 & $21,6 \mathrm{abB}$ & $21,1 \mathrm{aB}$ & $84,1 \mathrm{cA}$ \\
5 & $19,5 \mathrm{abB}$ & $22,7 \mathrm{aB}$ & $105,7 \mathrm{bA}$ \\
10 & $17,2 \mathrm{abB}$ & $23,2 \mathrm{aB}$ & $128,4 \mathrm{aA}$ \\
15 & $13,4 \mathrm{bB}$ & $23,3 \mathrm{aB}$ & \\
\hline Pré-tratamento & & & $109,4 \mathrm{abA}$ \\
\hline Controle & $23,1 \mathrm{aB}$ & $26,7 \mathrm{aB}$ & \\
ABA & $24,5 \mathrm{aB}$ & $20,5 \mathrm{aB}$ & $99,9 \mathrm{aA}$ \\
PEG & $15,1 \mathrm{aB}$ & $20,3 \mathrm{aB}$ & $79,9 \mathrm{bA}$ \\
\hline Coeficiente de variação $=31,5 \%$ & & & \\
\hline
\end{tabular}

Tabela 5. Condutividade elétrica ( $\mu$ S.g-1.cm-1) de embriões de Inga vera Willd. subsp. affinis (DC.) T.D.Pennington do estádio IV, submetidos a pré-tratamentos com solução de ABA (10-4 M) ou de PEG (-2,5 MPa), submetidos a três níveis de secagem e incubados por 15 dias a $-2{ }^{\circ} \mathrm{C}$ e 10 dias nas demais temperaturas. Médias seguidas pela mesma letra (minúsculas dentro das colunas, maiúsculas dentro das linhas) não diferem entre si pelo teste de Tukey a $5 \%$.

Table 5. Electrical conductivity $\left(\mu \mathrm{S} . \mathrm{g}^{-1} \cdot \mathrm{cm}^{-1}\right)$ of Inga vera Willd. subsp. affinis (DC.) T.D.Pennington embryos from age IV, submitted to pre-treatments with ABA $\left(10^{-4} \mathrm{M}\right)$ or PEG solution $(-2.5 \mathrm{MPa})$, submitted to three drying levels and incubated 15 days at $-2{ }^{\circ} \mathrm{C}$ and 10 days at other temperatures. Means followed by the same letter (lower case for columns, upper case for lines) do not differ by the Tukey test at $5 \%$.

\begin{tabular}{lccc}
\hline Temperaturas & Níveis de secagem & \\
\cline { 2 - 4 }$\left({ }^{\circ} \mathrm{C}\right)$ & Inicial & $1^{\mathrm{a}}$ secagem & $2^{\mathrm{a}}$ secagem \\
\hline-2 & $16,6 \mathrm{aB}$ & $19,5 \mathrm{aB}$ & $30,8 \mathrm{bA}$ \\
2 & $14,6 \mathrm{aB}$ & $20,9 \mathrm{aB}$ & $34,0 \mathrm{bA}$ \\
5 & $14,9 \mathrm{aB}$ & $15,7 \mathrm{aB}$ & $41,3 \mathrm{bA}$ \\
10 & $13,5 \mathrm{aB}$ & $17,7 \mathrm{aB}$ & $62,9 \mathrm{aA}$ \\
15 & $12,6 \mathrm{aB}$ & $18,2 \mathrm{aB}$ & $61,0 \mathrm{aA}$ \\
\hline Pré-tratamento & & & \\
Controle & $15,8 \mathrm{aB}$ & $20,6 \mathrm{aB}$ & $38,8 \mathrm{bA}$ \\
ABA & $15,1 \mathrm{aB}$ & $49,8 \mathrm{aA}$ \\
PEG & $12,3 \mathrm{aB}$ & $49,4 \mathrm{aA}$ \\
\hline Temperaturas & Pré-tratamentos & $14,5 \mathrm{aB}$ & \\
$\left({ }^{\circ} \mathrm{C}\right)$ & Controle & & PEG \\
\hline-2 & $24,2 \mathrm{aAB}$ & $\mathrm{ABA}$ & $14,7 \mathrm{bB}$ \\
2 & $25,0 \mathrm{aA}$ & $27,9 \mathrm{aA}$ & $18,3 \mathrm{bA}$ \\
5 & $21,6 \mathrm{aA}$ & $26,1 \mathrm{aA}$ & $21,9 \mathrm{bA}$ \\
10 & $28,1 \mathrm{aA}$ & $28,3 \mathrm{aA}$ & $35,3 \mathrm{aA}$ \\
15 & $26,4 \mathrm{aA}$ & $30,6 \mathrm{aA}$ & $36,6 \mathrm{aA}$ \\
\hline
\end{tabular}

Coeficiente de variação $=35,1 \%$ 
Tabela 6. Germinação (\%) de embriões de Inga vera Willd. subsp. affinis (DC.) T.D.Pennington do estádio III, submetidos a pré-tratamentos com solução de ABA (10-4 M) ou de PEG (-2,5 MPa), submetidos a três níveis de secagem e incubados por 15 dias a $-2{ }^{\circ} \mathrm{C}$ e 10 dias nas demais temperaturas. Médias seguidas pela mesma letra (minúsculas dentro das colunas, maiúsculas dentro das linhas) não diferem entre si pelo teste de Tukey a 5\%.

Table 6. Germination (\%) of Inga vera Willd. subsp. affinis (DC.) T.D.Pennington embryos from age III, submitted to pretreatments with ABA $\left(10^{-4} \mathrm{M}\right)$ or PEG solution $(-2.5 \mathrm{MPa})$, submitted to three drying levels and incubated 15 days at $-2{ }^{\circ} \mathrm{C}$ and 10 days at other temperatures. Means followed by the same letter (lower case for columns, upper case for lines) do not differ by the Tukey test at $5 \%$.

\begin{tabular}{lccc}
\hline Temperaturas & \multicolumn{2}{c}{ Níveis de secagens } & \\
\cline { 2 - 4 }$\left({ }^{\circ} \mathrm{C}\right)$ & Inicial & $1^{\mathrm{a}}$ secagem & $2^{\mathrm{a}}$ secagem \\
\hline-2 & $69,4 \mathrm{bB}$ & $95,0 \mathrm{aA}$ & $35,0 \mathrm{aB}$ \\
2 & $86,7 \mathrm{aA}$ & $91,1 \mathrm{aA}$ & $22,8 \mathrm{bcB}$ \\
5 & $89,4 \mathrm{aA}$ & $91,1 \mathrm{aA}$ & $15,0 \mathrm{cdB}$ \\
10 & $85,0 \mathrm{aA}$ & $91,7 \mathrm{aA}$ & $8,3 \mathrm{~dB}$ \\
15 & $94,4 \mathrm{aA}$ & $90,5 \mathrm{aA}$ & $34,4 \mathrm{abB}$ \\
\hline Pré-tratamento & & & $17,0 \mathrm{bB}$ \\
\hline Controle & $82,3 \mathrm{aA}$ & $86,0 \mathrm{bA}$ & $17,7 \mathrm{bC}$ \\
ABA & $84,0 \mathrm{aB}$ & $93,0 \mathrm{abA}$ & $34,7 \mathrm{aC}$ \\
\hline
\end{tabular}

Coeficiente de variação $=13,6 \%$

efeitos somados da secagem e da aplicação do PEG foram prejudiciais, especialmente para oxidação após a primeira secagem (figuras 2 e 5 ).

A aplicação do ABA, diferentemente do observado por Barbedo \& Cicero (2000), teve efeitos muito pequenos, como a diminuição da oxidação dos embriões do estádio III a 2,5 e $10^{\circ} \mathrm{C}$ e do estádio IV em todas as temperaturas positivas. É possível que a concentração do ABA, ou o tempo de exposição (ou ambos), tenha sido insuficiente para promover grandes modificações. É possível, ainda, que os embriões apresentassem menor sensibilidade ao ABA. Deve-se lembrar que sementes recalcitrantes não passam pela fase de secagem típica das ortodoxas, marcando a divisão entre formação/maturação e germinação. Portanto, é bastante difícil se identificar, para tais sementes, se ainda estão em processo de maturação ou se já se encontram germinando, e quanto mais avançado o processo de germinação, menor será a sensibilidade ao ABA (Pammenter et al. 1994, Barbedo \& Marcos Filho 1998, Bilia \& Barbedo 1997, Barbedo \& Bilia 1998, Marcos Filho 2015, Barbedo 2018). Particularmente para Inga vera, já foi possível identificar sementes com evidentes sinais de germinação no estádio III, ainda dentro do fruto (Caccere et al. 2013).
Diante do exposto, pode se concluir que a escolha do estádio de maturação é decisiva para melhor conservar os embriões de Inga vera ssp. affinis. A sensibilidade desses embriões à dessecação e à redução de temperatura está relacionada diretamente com estádio de maturação. Devido à intensa atividade metabólica desses embriões, observaram-se processos que não o respiratório, que podem ser responsáveis pela dificuldade de sua conservação. A pequena redução do teor de água, pela secagem ou pela aplicação de déficit hídrico com solução de PEG, também mostrou benefícios, reduzindo tanto a respiração, nas temperaturas mais elevadas, quanto a oxidação, nas mais baixas. A dificuldade em conservar a viabilidade fisiológica das sementes dessa espécie se dá, provavelmente, devido ao seu elevado metabolismo e dos processos não respiratórios observados. Uma pequena redução no teor de água, por secagem direta ou pela utilização de soluções osmóticas, de sementes recém-colhidas, pode melhorar a sua tolerância tanto à dessecação quanto às baixas temperaturas. A redução da temperatura de armazenamento, até níveis que não permitam o congelamento dos tecidos, é realmente eficiente na redução do metabolismo, diminuindo as taxas respiratórias das sementes e ampliando o seu potencial de armazenamento. 
Tabela 7. Germinação (\%) de embriões de Inga vera Willd. subsp. affinis (DC.) T.D.Pennington do estádio IV, submetidos a pré-tratamentos com solução de ABA (10-4 M) ou de PEG (-2,5 MPa), submetidos a três níveis de secagem e incubados durante 15 dias a $-2{ }^{\circ} \mathrm{C}$ e 10 dias nas demais temperaturas. Médias seguidas pela mesma letra (minúsculas para comparação entre temperaturas, maiúsculas entre pré-tratamentos e itálico entre os conteúdos de água) não diferem entre si pelo teste de Tukey a $5 \%$.

Table 7. Germination (\%) of Inga vera Willd. subsp. affinis (DC.) T.D.Pennington embryos from age IV, submitted to pretreatments with $\mathrm{ABA}\left(10^{-4} \mathrm{M}\right)$ or PEG solution $(-2.5 \mathrm{MPa})$, submitted to three drying levels and incubated 15 days at $-2^{\circ} \mathrm{C}$ and 10 days at other temperatures. Means followed by the same letter (lower case for temperature comparison, upper case for pre-treatment comparision and italics for water content comparision) do not differ by the Tukey test at $5 \%$.

\begin{tabular}{|c|c|c|c|}
\hline \multirow{2}{*}{$\begin{array}{l}\text { Temperaturas } \\
\left({ }^{\circ} \mathrm{C}\right)\end{array}$} & \multicolumn{3}{|l|}{ Pré-tratamentos } \\
\hline & Controle & $\mathrm{ABA}$ & PEG \\
\hline \multicolumn{4}{|c|}{ Sem secagem } \\
\hline-2 & $90,0 \mathrm{aA} A B$ & $96,7 \mathrm{aA} A$ & $100,0 \mathrm{aA} A$ \\
\hline 2 & $95,0 \mathrm{aA} A$ & $91,7 \mathrm{aA} A$ & 98,3 aA $A$ \\
\hline 5 & $96,7 \mathrm{aA} A$ & $91,7 \mathrm{aA} A$ & $95,0 \mathrm{aA} A$ \\
\hline 10 & $85,0 \mathrm{aA} A$ & $98,3 \mathrm{aA} A$ & $96,7 \mathrm{aA} A$ \\
\hline 15 & $98,3 \mathrm{aA} A$ & $96,7 \mathrm{aA} A$ & $91,7 \mathrm{aA} A$ \\
\hline \multicolumn{4}{|c|}{$1^{\mathrm{a}}$ secagem } \\
\hline-2 & $96,7 \mathrm{aA} A$ & $83,3 \mathrm{aA} A$ & $90,0 \mathrm{aA} A$ \\
\hline 2 & $100,0 \mathrm{aA} A$ & $81,7 \mathrm{aB} A$ & $98,3 \mathrm{aA} A$ \\
\hline 5 & 93,3 aA $A$ & $80,0 \mathrm{aA} A$ & $95,0 \mathrm{aA} A$ \\
\hline 10 & 93,3 aA $A$ & $85,0 \mathrm{aA} A$ & 86,7 aA $A$ \\
\hline 15 & $96,7 \mathrm{aA} A$ & $91,7 \mathrm{aA} A$ & $96,7 \mathrm{aA} A$ \\
\hline \multicolumn{4}{|c|}{$2^{\mathrm{a}}$ secagem } \\
\hline-2 & $78,3 \mathrm{aA} B$ & $50,0 \mathrm{abB} B$ & $61,7 \mathrm{abB} B$ \\
\hline 2 & $73,3 \mathrm{abA} B$ & $46,7 \mathrm{bcB} B$ & $76,7 \mathrm{aA} B$ \\
\hline 5 & $66,7 \mathrm{abA} B$ & $31,7 \mathrm{cC} B$ & $50,0 \mathrm{bB} B$ \\
\hline 10 & $60,0 \mathrm{bA} B$ & $38,3 \mathrm{bcB} B$ & $50,0 \mathrm{bAB} B$ \\
\hline 15 & $18,3 \mathrm{cC} B$ & $65,0 \mathrm{aA} B$ & $48,3 \mathrm{bB} B$ \\
\hline
\end{tabular}

\section{Literatura citada}

Andréo, Y., Nakagawa, J. \& Barbedo, C.J. 2006. Mobilização de água e conservação da viabilidade de embriões de sementes recalcitrantes de ingá (Inga vera Will. subsp. affinis (DC.) T.D.Pennington). Revista Brasileira de Botânica 29: 309-318.

Bailly, C. 2004. Active oxygen species and antioxidants in seed biology. Seed Science Research 14: 93-107.

Barbedo, C.J. 2018. A new approach towards the so-called recalcitrant seeds. Journal of Seed Science 40: 221-236.

Barbedo, C.J. \& Bilia, D.A.C. 1998. Evolution of research on recalcitrant seeds. Scientia Agricola 55 (especial): 121-125.

Barbedo, C.J., \& Cicero, S.M. 1998. Utilização do teste de condutividade elétrica para previsão do potencial germinativo de sementes de ingá. Scientia Agricola 55: 249-259.
Barbedo, C.J. \& Cicero, S.M. 2000. Effects of initial quality, low temperature and ABA on the storage of seeds of Inga uruguensis, a tropical species with recalcitrant seeds. Seed Science and Technology 28: 793-808.

Barbedo, C.J. \& Marcos Filho, J. 1998. Tolerância à dessecação em sementes. Acta Botanica Brasilica 12: 145-164.

Barbedo C.J., Centeno D.C. \& Figueiredo-Ribeiro R.C.L. 2013. Do recalcitrant seeds really exist? Hoehnea 40: 583-593.

Barbedo, C.J., Silva, J.P.N., Fançoso, C.F. \& Parisi, J.J.D. 2018. Armazenamento de sementes. In: C.J. Barbedo \& N.A. Santos Junior (orgs.). Sementes do Brasil: produção e tecnologia para espécies da flora brasileira. Instituto de Botânica, São Paulo. pp. 81-108.

Berjak, P. \& Pammenter, N.W. 2008. From Avicennia to Zizania: seed recalcitrance in perspective. Annals of Botany 101: 213-228. 
Berjak, P., Sershen., Varghese, B. \& Pammenter, N.W. 2011. Cathodic amelioration of the adverse effects of oxidative stress accompanying procedures necessary for cryopreservation of embryonic axes of recalcitrantseeded species. Seed Science Research 3: 187-203.

Bilia, D.A.C. \& Barbedo, C.J. 1997. Estudos de germinação e armazenamento de sementes de Inga uruguensis Hook. et Arn. Científica 25: 379-391.

Bilia, D.A.C., Marcos Filho, J. \& Novembre A.D.C.L. 1998. Conservação da qualidade fisiológica de sementes de Inga uruguensis Hook. et Arn. Revista Brasileira de Sementes 20: 48-54.

Bonjovani, M.R. \& Barbedo, C.J. 2008. Sementes recalcitrantes: intolerantes a baixas temperaturas? Embriões recalcitrantes de Inga vera Willd. subsp. affinis (DC.) T. D. Penn. toleram temperatura sub-zero. Revista Brasileira de Botânica 31: 345-356.

Bonjovani, M.R. \& Barbedo, C.J. 2014. Induction of tolerance to desiccation and to subzero temperatures in embryos of recalcitrant seeds of inga. Journal of Seed Science 36: 419-426.

Bonjovani, M.R. \& Barbedo, C.J. 2019. Respiration and deterioration of Inga vera ssp. affinis embryos stored at different temperatures. Journal of Seed Science 41: 44-53.

Brasil. Ministério da Agricultura Pecuária e Abastecimento. 2009. Regras para análise de sementes, Brasília.

Caccere, R., Teixeira, S.P., Centeno, D.C., FigueiredoRibeiro, R.C.L. \& Braga, M.R. 2013. Metabolica and structural changes during early maturation of Inga vera seeds are consistent with the lack of a desiccation phase. Journal of Plant Physiology 170: 791-800.

Chandra, J., Sershen, Verghese, B. \& Keshavkant, S. 2019. The potential of ROS inhibitors and hydrated storage in improving the storability of recalcitrant Madhuca latifolia seeds. Seed Science and Technology 47: 33-45.

Colville, L. \& Pritchard, H.W. 2019. Seed life span and food security. New Phytologist 224: 557-562.

Dahal, P., Kim. N.S. \& Bradford, K.J. 1996. Respiration and germination rates of tomato seeds at suboptimal temperatures and reduced water potentials. Jornal of Experimental Botany 47: 941-947.

Faria, J.M.R. 2006. Desiccation tolerance and sensitivity in Medicago truncatula and Inga vera seeds. $\mathrm{PhD}$ Thesis, Wageningen University, Wageningen, The Netherlands.

Feltre, R. 2004. Química geral. 6.ed. Moderna, São Paulo.

Hendry, G.A.F. 1993. Oxygen, free radical processes and seed longevity. Seed Science Research 3: 141-153.
IAG/USP. 2017. Boletim climatológico anual da Estação Meteorológica do IAG/USP, Seção Técnica de Serviços Meteorológicos, v.20. Instituto de Astronomia, Geofísica e Ciências Atmosféricas da Universidade de São Paulo, São Paulo.

Kader, A.A. \& Saltveit, M.E. 2002. Respiration and gas exchange. I: J.A. Bartz, J.K. Brecht \& J. Weichmann (orgs.). Postharvest physiology and pathology of vegetables. Marcel Deckker, New York, pp.7-29.

Lamarca, E.V. 2009. Taxas respiratórias e velocidade de deterioração de sementes de Caesalpinia echinata Lam. em função de variações hídricas e térmicas. Dissertação de Mestrado. Instituto de Botânica, São Paulo.

Marcos Filho, J. 2015. Fisiologia de sementes de plantas cultivadas. 2.ed. ABRATES, Londrina.

Michel, B.E. \& Kaufmann, M.R. 1973. The osmotic potential of polyethylene glicol 6000. Plant Physiology 51: 914-916.

Pammenter, N.W. \& Berjak, P. 2000. Aspects recalcitrant seed physiology. Revista Brasileira de Fisiologia Vegetal 12: 56-69.

Pammenter, N.W., Berjak, P., Farrant, J.M., Smith, M.T. \& Ross, G. 1994. Why do stored hydrated recalcitrant seeds die? Seal Science Research 4: 187-191.

Parisi, J.J.D., Biagi, J.D., Barbedo, C.J., Medina, P.F. \& Lamarca, E.V. 2019. Respiratory rates of Inga vera Willd. subsp. affinis (DC.) T. D. Penn. seeds. Floresta e Ambiente 26: 1-10.

Ruelland, E. \& Zachowski, A. 2010. How plants sense temperature. Environmental and Experimental Botany 69: 225-232.

Santana, D.G. \& Ranal, M. 2004. Análise da germinação: um enfoque estatístico. Ed. Universidade de Brasília, Brasília.

Santos, I.R.I. 2001. Criopreservação de germoplasma vegetal. Biotecnologia, Ciência e Desenvolvimento 20: 60-65.

Taiz, L. \& Zeiger, E. 2004. Fisiologia vegetal. 3.ed. Artmed, Porto Alegre.

Vertucci, C.W. 1993. Predicting the optimum storage conditions for seeds using thermodynamic principles. Journal of Seed Technology 17: 41-53.

Vertucci, C.W. \& Farrant, J.M. 1995. Acquisition and loss of desiccation tolerance. In: Seed development and germination (J. Kigel \& G. Galili, eds.). Marcel Dekker Inc., New York, pp. 237-271.

Villela, F.A. \& Peres, W.B. 2004. Coleta, beneficiamento e armazenamento. In: Germinação: do básico ao aplicado (A.G. Ferreira \& F. Borghetti, orgs.). Artmed, Porto Alegre, pp. 265-281.

Walters, C., Wheeler, L.M. \& Grotenhuis, J.M. 2005. Longevity of seeds stored in a genebank: species characteristics. Seed Science Research 15: 1-20. 